\title{
Educación e construción nacional en Rousseau. Arredor do Emilio e das consideracións sobre o goberno de Polonia
}

No Libro Primeiro do Emilio, cando Jean-Jacques Rousseau abre a ensarillada problemática do home e do cidadán e apela, unha vez máis, á Historia e ás orixes —coma no Discurso sobre a orixe e os fundamentos da desigualdade entre os homes ou no Contrato Social-, atopamos algunhas afirmacións, non se sabe se provocadoras ou enigmáticas, que nos chimpan de cabeza nunha das cuestións políticas máis quentes do XVIII europeo... Estou a falar das relacións Condición humana (Ser natural/Ser social en Rousseau)Sociedade-Nación (Patria)-Estado-Educación.

Sabido é que esta complexa cadea de correlacións ficaría -e fica- simplificada se obviamos no seu primeiro elemento (a "condición humana») o concepto metafísico rousseauniano de "ser natural». "Ser natural» —ou «natureza humana»- equivale en Rousseau a "alma humana» ou "esencia humana", a "natureza eterna» ou "esencia universal». Trátase, por tanto, da insalvable débeda rousseauniana coa súa concepción relixiosa e dualista do mundo. Condicionamento, pois, de base que alterará en boa medida o seu discurso político-pedagóxico sobre o home como «ser social». Pero que non sempre o invalida. Polo contrario, ás veces, mesmo resulta potenciado.

Para Rousseau, o home como "ser social» será sempre o referente do home como "ser natural». E non á inversa. Cando o pensador-sentidor de Xenebra (como dicía Carlos Lerena) fala das contradicións do home e o cidadán, está partindo desta equivalencia: home=ser natural e cidadán=ser social. Para Rousseau, o cidadán non poderá nin deberá deixar de ser home (¿que «home? Un Home «natural», un home "universal», un home «eterno»..., aínda que un home "novo» e «renacido» dos desastres incontrolados da Historia e capaz de establecer un novo contrato social).

Velaí a parte vulnerable e metafísica do seu discurso antropolóxico. Velaí 0 «esencialismo» e o «idealismo» de partida que eiva o seu discurso... Pero - e agora vén o que nos interesa-, o home só poderá ser tal se é un «bo cidadán». Se o home non chega a ser un cidadán «libre» e «consciente», non será nada. Nin sequera será home.

Hai que escribir home. Porque Rousseau dicía home. Inequivocamente. Cando falamos de Rousseau non se pode omitir a expresión sexista. Non podemos falar de seres humanos (homes e mulleres). E é que Rousseau teorizaba sobre unha sociedade «de homes», sobre unha sociedade «machista» e «sexista» da que as mulleres fican á marxe, 
recluídas exclusivamente no espazo doméstico e fóra do contrato social (outra limitación que sesga de raíz o seu discurso sociolóxico e político).

Se partimos, en cambio, do concepto de "ser humano" como "ser social», da "esencia humana» como "conxunto das relacións sociais dos seres humanos" -tal e como 0 entendía Marx - debemos arrumbar por completo o concepto rousseauniano do «home» como "ser natural» e ficar instalados na pura "sociabilidade" e "historicidade" dos seres humanos como construtores revolucionarios da súa propia historia, da súa propia vida e, polo tanto, da súa verdadeira esencia e única naturaleza realmente cognoscible e posible.

Pero tamén aí —aínda que coas limitacións apuntadas- Rousseau tan moitas cousas que dicir. Cousas que atopamos no Discurso, no Contrato e no Emilio. Cousas que afectan todas elas ó resto dos elementos de cadea Sociedade-Nación (Patria)-EstadoEducación.

\section{Emilio}

«Todo o que non temos ó nacer e do que non podemos privarnos fóisenos dado pola educación". " Subliñamos iso: "e do que non podemos privarnos" (porque deixaríamos de ser nós mesmos). Educación como sinónimo de circunstancias, medio ou entorno. Máis tarde, Robert Owen insistirá nesa especie de «asulagamento nas circunstancias». E Marx, nunha das teses sobre Feuerbach, matizará: somos un produto das circunstancias, pero as circunstancias tamén son producidas por nós. Os educadores tamén deberán ser educados. E anos despois, Ortega y Gasset: «yo soy yo y mi circunstancia». Volta a Rousseau. 0 home e a circunstancia. Separación antidialéctica. Conservación dunha liberdade ilusoria. O home dominante ás circunstancias ("yo soy yo», en primeiro lugar). O home como «produtor», pero xa non tan claramente como "produto». O home -en tanto que individuocomo detentador da última vontade e a última palabra. En definitiva, en Ortega - como en Rousseau-, o home soberana e ilusoriamente libre.

Fala despois o noso autor de tres clases de educación: a educación "da natureza», a educación "dos homes» e a educación "das cousas». Educación "natural» determinada polas características específicas de cada quen (arrancando sempre desa imposible «esencia natural eterna», desa quimera na que aínda está sumido o idealismo pedagóxico que nos invade); educación que recibimos en contacto cos demais (viciada polo secuestro, reclusión e infantilización da infancia, en que caerán tódalas correntes pedagóxicas neorrousseaunianas); por último, educación «técnica» de habilidades e destrezas. Chegará un momento —di Rousseau- en que a harmonización destes tres tipos de educación non é posible. E temos que escoller:

¿Que podemos facer cando [as tres clases de educación] son opostas e en vez de educar a un home para si propio quéreno educar para os demais? A harmonía, daquela, resulta imposible, e forzados a opoñernos á natureza ou ás institucións sociais, é preciso escoller

1 Citamos da antoloxía de Emilio o de la educación, Fontanella, Barcelona, 1973, preparada en francés por $\mathrm{H}$. Wallon e J.L. Lecercle e traducida ó español por Antonio G. Valiente. 
entre formar a un home ou un cidadán, pero non podemos facer a un e outro ó mesmo tempo. ${ }^{2}$ [Os subliñados son nosos].

Rousseau formula aquí a dicotomía home/cidadán (ser natural/ser social) no contexto específico e concreto do Antigo Réxime e da sociedade do seu tempo. A súa mensaxe é: nesta sociedade, con estas características nacionais e con tal estrutura estatal, non pode haber harmonía entre unha educación «natural» auténtica e unha educación cívica racional. En consecuencia, será preciso cambiar a sociedade, a forma de goberno e o Estado, para conseguir así mellores resultados na obra educativa. Ou o que é o mesmo: sen un novo contrato social que liquide tódolos elementos corruptores do progreso (liquidación das desigualdades históricas orixinadas coa aparición da propiedade privada -Discurso-), non poderá implantarse un novo tipo de educación.

Jean-Jacques entende a educación como un acto creativo, como a forma par excellence da rehumanización dos homes, como a conquista das máis altas cotas de liberdade (aínda que só conseguirá meternos máis no fondo do círculo maldito e recorrente da represión/liberación, como diría Lerena), como un acto de produción cultural, como a quintaesencia do entorno e as circunstancias. Aparentemente, considera o cambio social -a revolución, para ser máis precisos - como primeira fase á hora de implantar o seu novo concepto de educación. Pero como era un pensador decididamente dialéctico -recordemos as observacións de Engels sobre o Discurso en tanto que precursor da dialéctica hegeliana-, sabe que non hai fases nidiamente diferenciadas no tempo e no espazo. Sabe que non hai propiamente nestes cambios un «antes» e un "despois», senón pura simultaneidade. (Non hai transformación social e política posible se non vai acompañada dunha transformación educativa. E viceversa...).

Insensiblemente, Rousseau pasa desta consideración teórica da educación como importantísima práctica técnica e científica a unha consideración da educación como aparato ideolóxico ó servizo do Estado (recordemos a L. Althusser: «O aparato ideolóxico escolar do Estado como aparato dominante»...). Ademais de "práctica técnica», a educación é unha «práctica social». Técnica e ciencia, si, pero tamén ideoloxía. Inseparables unha da outra. Dúas caras da mesma moeda.

Insensiblemente, pero inexorablemente, Rousseau transita da súa concepción pedagóxica "naturalista», "humanista», etc. á cuestión capital da educación como aparato de Estado. O tema fica "enigmaticamente» enunciado no Emilio e firmemente abocetado nun dos seus últimos escritos: Consideracións sobre o goberno de Polonia. E, para facelo, Rousseau recorre á abordaxe - a unha primeira abordaxe — da cuestión nacional, do sentimento patriótico, da estrutura do novo Estado e das relacións nación-Estado. O filósofo de Xenebra ten, pois, cousas que dicir sobre educación e instrución pública, aínda que case sempre o diga entre liñas (parece que a pedagoxía priváballe máis que a política educativa de Estado; era máis un «doctrinario» - como di Aníbal Ponce- que un pedagogo «metido» en política). La Chalotais, por exemplo, escribirá o seu Ensaio de educación nacional

2 Ibídem, p. 97. 
e plan de estudios para a xuventude cunha formulación máis explicitamente política, pero manténdose no ámbito de reforma e sen o calado revolucionario da obra de Rousseau. Porque é con Rousseau con quen aparece o tema de fondo que dá título a este traballo: a educación e a construción nacional. Helvétius non faría máis que perfilar a proposta rousseuniana: a educación como asunto constitucional dos Estados. A Revolución de 1789 faría o resto...

Pero volvamos ó Emilio... Inmediatamente despois da cita anterior, di Rousseau:

Toda sociedade parcial, cando está estreitamente unida, afástase do grande. Todo patriota é duro cos estranxeiros; eles non son máis ca homes e non valen nada ó seu modo de ver. Este inconveniente é inevitable, pero ten pouca importancia. $O$ esencial está en ser bo coas xentes con que vive. De murallas afora, o espartano era ambicioso, avaro, inicuo, pero 0 desinterese, a equidade e a concordia reinaban dentro dos seus muros. Non vos fiedes dos cosmopolitas que van lonxe buscar nos seus libros deberes que non se dignan cumprir en torno deles. Esta filosofía practícana os tártaros, sen importarlles o ben dos seus veciños. ${ }^{3}$ [Subliñados nosos].

Reparemos no inicio desta cita: «toda sociedade parcial, cando está estreitamente unida, afástase do grande». O referente é, neste caso, a teoría platónica do Estado: é máis fácil ordenar e gobernar un Estado pequeno que un Estado grande. Son variadas as alusións de Rousseau a este tema en distintos lugares da súa obra (pensemos, por exemplo, no agarimo con que Rousseau fala da súa patria pequena, do seu lugar, da República de Xenebra). O noso filósofo é non só o cumio do pensamento contractualista moderno, senón tamén un igualitarista avant la lettre. Rousseau é o teórico apoloxeta do pequeno: pequenos Estados, pequenas propiedades, pequenos negocios, traballos miúdos... ipequena burguesía! Mesmo adoraba as casas pequenas e os espazos pequenos ("nunca vin tantas plantas en tan pouca terra», díxolle un día Bernardin de Saint-Pierre ó contemplar os testos florais que tiña na súa casa das aforas de París...).

«Todo patriota é duro cos estranxeiros»... Expresión enigmática (?) que Rousseau matizaría nun párrafo que tería sido incluído na primeira edición, despois suprimido e logo reposto como nota a pé de páxina:

... Por iso as guerras das repúblicas son máis crueis que as das monarquías. Pero se a guerra dos Reis é moderada, a súa paz é terrible, e é mellor ser o seu inimigo que o seu vasallo. ${ }^{4}$

Velaí unha incitación á rebelión contra as formas de goberno do Antigo Réxime, unha exhortación revolucionaria. É mellor a guerra contra a tiranía que esa «paz terrible» da servidume. Non parece raro que, poucos anos despois, un dos "dereitos do home e do cidadán» fose o dereito a rebelarse contra a opresión... 
"O esencial está en ser bo coas xentes con quen vive"... Isto é, non só en ser un bo patriota - de portas afora - senón un bo compatriota - para cos seus-. Unha vez máis, estamos diante dunha débeda de Rousseau coa teoría platónica do Estado: que os nosos gardiáns sexan feros e implacables cos nosos inimigos, pero mansos e doces con nós mesmos -así como son os cans cos seus amos...-. Referencia directa a Esparta, que se repite en Rousseau (¡cantas voltas daría ó longo da Historia este papel que deberían xogar os aparatos represivos do Estado!). De calquera maneira, «non vos fiedes dos cosmopolitas"...

Pouco máis adiante, «navegando» no seu imposible dualismo ser natural/ser social, dirá:

As boas institucións sociais son aquelas que posúen o medio de desnaturalizar ó home, quitarlle a súa existencia absoluta para reemprazala por outra relativa e transportar o eu dentro da unidade común; de tal maneira que cada particular non se crea un, senón parte da unidade común e sexa sensible somentes no todo. ${ }^{5}$ [Subliñados nosos].

Como vemos, o cidadán imponse ó home natural. E Rousseau exemplifica:

Un cidadán de Roma non era nin Caio nin Lucio; era un romano que amaba exclusivamente á súa patria por ser a súa... Me parece que esto non ten moita relación cos homes que coñecemos...

O lacedemonio Paderetes presentouse para ser admitido no Consello dos Trescentos e, rexeitado, volveuse á súa casa contento de que houbera en Esparta trescentos homes que o avantaxaban en mérito... Velaí o cidadán.

Unha espartana tiña cinco fillos no exército e agardaba noticias da batalla. Chega un ilota. Ela pregúntalle tremendo. Dille el: "os vosos cinco fillos morreron». Responde ela: «Vil escravo, ¿preguntaba eu iso?» «Fomos nós os que conseguimos a vitoria...». A nai corre cara o templo a darlle gracias ós deuses. Velaí a cidadá...

Aquel que na orde civil quere conservar a primacía dos sentimentos naturais, non sabe 0 que quere. Sempre en contradición consigo e flutuando entre as súas inclinacións e os seus deberes, non será nunca nin home nin cidadán, nin será bo para el nin para os demais. Será un dos homes dos nosos días, un francés, un inglés, un burgués; non será nada. ${ }^{6}$ [Subliñados nosos].

Cita longa e importantísima para o tema que nos ocupa. Rousseau pugna esforzadamente por vencellar "educación» e "construción nacional». Sabe que o sentimento nacional está en crise como consecuencia da crise social do absolutismo. E sabe que non é posible unha solución por separado. Apela a Plutarco nos exemplos citados como lección suprema de humildade e de sacrificio pola patria (sacrificio que sería brutalmente instrumentalizado en moitos episodios bélicos e de opresión política, ó longo da Historia). Considera inviable a posta en marcha dun novo programa educativo se non se acomete

5 Ibídem, p. 98

6 lbídem, pp. 98-99. 
unha transformación radical da estrutura do Estado e unha revitalización do sentimento nacional e do patriotismo.

Por iso:

Se queredes formarvos unha idea da educación pública, lede $A$ República de Platón. Non é unha obra de política, como pensan os que xulgan os libros polo seu título, senón que é o máis excelente tratado de educación que se teña escrito. ${ }^{7}$

E cando afirma decidido que «toda sociedade parcial, cando está estreitamente unida, afástase do grande», está a avanzar, consciente ou inconscientemente, a necesidade de que o Estado sexa a institución suprema de cada nación. Non só vemos aquí ó Rousseau ideólogo da pequena burguesía, senón tamén ó Rousseau das pequenas nacións, das pequenas patrias, dos pequenos Estados... Por iso di: "Onde non hai patria, non pode haber cidadáns».

Do anterior, dedúcese que, para Rousseau, nin os franceses se estaban a «comportar» como auténticos franceses, nin os ingleses como auténticos ingleses, nin ningún outro europeo aparecía, antes que como europeo, como cidadán do seu propio país. Nada novo hoxe, por outra parte. Entre outros, xa Xosé Stalin, no seu famoso libriño $O$ marxismo e a cuestión nacional, deixou dito:

A nación non é simplemente unha categoría histórica, senón unha categoría histórica dunha determinada época, a época do capitalismo ascendente. 0 proceso de liquidación do feudalismo e do desenvolvemento do capitalismo é, ó mesmo tempo, o proceso en que os homes se constitúen en nacións.

Por outra parte, a sensibilidade de Rousseau para a cuestión nacional aparece con certa frecuencia na súa obra. Sensibilidade e agudo sentido de observación do problema. Escribirá un día -trátase tamén dun dos seus escritos políticos últimos- un Projet de constitution pour la Corse, no que se recrea na descrición detallada de Córcega e en como ordenar aquel Estado. (Pasarían despois moitas cousas para que o xoven Napoleón Bonaparte, lector apaixonado de Rousseau na súa mocidade, cortara radicalmente coas súas raíces meridionais e decidira mesmo renegar das súas orixes italianas: Buonaparte... Albert Manfred explica polo miúdo os porqués, na súa formidable biografía do célebre corso... O pequeno capitán moreno e cetrino quería ser máis branco de pel e vivir no Norte. ¿Podería falarse xa de tensión Norte/Sul?).

Nalgún lugar das Confesións, cando Rousseau fala do seu amigo español Manuel Ignacio de Altuna — vasco, de Azkoitia-, asómbrase de que sexa «alto, louro e de ollos claros»; e de que non teña a "violencia interior» que se supón nos españois; e de que fora «apaixonado, pero non vingativo nin rencoroso..." De ter feito Jean-Jacques aquel frustrado viaxe a Azkoitia é seguro que descubriría o feito diferencial vasco...

7 Ibídem. 
Tamén nas Confesións aparecen, aquí e acolá, referencias ós costumes nacionais suízos, franceses, italianos. Apreciacións, feitas sempre con deleitación, sobre gustos, aspectos da vida de cada día, similitudes, diferencias... En calquera caso, con empeño especial en establecer riscos definidores das identidades nacionais. Parece que estaba claro, en Rousseau, que non podía ser posible a europeidade se antes non se pasaba por ser auténtica e xenuinamente francés, inglés ou alemán. Cousa por demais estraña nun século tan uniformizador, centralizador e despreocupado por eses temas como é o XVIII europeo. Fenómeno, en cambio, que se expande arroladoramente no XIX. Dá a impresión de que Rousseau escribía - polo menos neste caso- para o futuro (Jean-Jacques cáseque sempre está a anunciar o XIX...).

Pierre Vilar, na súa maxistral Historia de España, apunta o fenómeno invertido, no caso de España. Descentralización no XVIII e centralismo forzado no XIX (época dos nacionalismos europeos). Tamén Marx, na súa España revolucionaria, fala dese poder esmigallado do XIX español, contra o que combate a duras penas o centralismo (o que el chama poderes «municipais, "comarcais» e "provinciais», herdeiros desa descentralización do noso XVIII e, sobre todo, das «peculiaridades do absolutismo español»).

\section{Consideracións...}

Cando Rousseau escribe as Considérations sur le gouvernement de la Pologne (en xuño/xullo de $1771,{ }^{8}$ con algúns retoques en abril de 1772), está xa nos anos finais da súa vida. Nesta pequena obra, tan madura, tan plena e tan matizada, Rousseau aquilata ó máximo cáseque todo o que di. Vacila xa no mesmo título do escrito. ¿ «Goberno»? ¿ “Constitución»? ¿ «República»? ${ }^{9} E$ asómbrase de que os polacos, arrinconados naquel momento nun pequeno territorio - como el di-, sexan, moral e politicamente, tan ambiciosos e tan ousados como para pretender poñer en marcha un proceso constitucional e unha reestruturación do Estado, que lle encargan a el con decisión, con apremio e mesmo con ansiedade.

A obra ten varias partes: «estado da cuestión» (e "cuestión de Estado», si...), «espírito das vellas institucións», «educación», "ordes estamentais», "constitución», «sobre 0 Rei», «sistema económico», «sistema militar», «leis», «administración» e, por último, un proxecto de posta en marcha.

Para o caso que nos ocupa, interésanos agora particularmente a "cuestión educativa». Entre outras razóns de método (véxase o título deste traballo), porque é, paréceme, a única obra na que Jean-Jacques se ocupa practicamente da educación como asunto de Estado. Trátase de apenas un esbozo, como o mesmo Rousseau di. Pero nese pequeno capítulo da pequena obra rousseauniana está todo o seu pensamento de fondo sobre a educación pública.

8 Vid. Michel Launay, «Presentation, Notes et Dictionnaire politique et Philosophique de Rousseau», en Oeuvres Complètes, París, Seuil, 1967-71, vol. 3, p. 527.

9 Ibídem. 
C'est ici l'article important, empeza dicindo. A educación como asunto principal para a transformación do Estado e para a reprodución dos sinais de identidade nacionais. ${ }^{10}$ «É a educación a que debe dar ás almas a forma nacional» —di. Explicación rotunda da educación como xeradora e inculcadora da ideoloxía e da conciencia nacional («forma nacional»). E engade: «para que sexan patriotas por inclinación, por paixón, por necesidade». Educación da sensibilidade, educación dos sentimentos, que Rousseau relaciona inmediatamente coas formas concretas e prácticas da existencia cívica e política:

Todo verdadeiro republicano mamou, co leite da súa nai, o amor pola súa patria, isto é, o amor polas leis e pola liberdade.11

Así pois, «a educación nacional só corresponde ós homes libres». Primeiro deseño das primeiras formas de educación nacional que corresponderían a un Estado de novo tipo (oposto ó Estado absolutista).

E insiste no tema xa apuntado no Emilio: «Un francés, un inglés, un español, un italiano, un ruso, son todos, máis ou menos, o mesmo home [falta dunha clara conciencia nacional]. Ós vinte anos, un polaco debe ser... un polaco. E debe ter por mestres só polacos». E pouco máis adiante: «Tratade por tódolos medios de non converter o estado de pedagogo nun oficio. Todo home público en Polonia non debe ter máis estado permanente que o de cidadán» (a división do traballo e a profesionalización non daban para máis...).

En realidade, Rousseau amósanos eiquí o verde que estaba daquela a cuestión nacional en Europa. Federico Engels, un século despois e nunha carta a Kautsky do 7 de febreiro de 1882, diría — a propósito da independencia de Polonia-: "O movemento internacional do proletariado só é posible a priori entre nacións independentes»... Ou: «A colaboración internacional só é posible entre iguais»... «Mentres Polonia estea dividida e sometida, non pode desenvolverse ningún partido socialista importante no país». E, máis adiante, engade: «Así pois, na miña opinión, hai dúas nacións en Europa que teñen non somente 0 dereito senón o deber de ser nacionais antes que internacionais: os irlandeses e os polacos. Canto máis nacionais sexan, máis internacionais serán"... 0 que coincide cos planteamentos de Rousseau: non hai Europa posible se antes non se consolidan e afianzan os Estados que deben conformala. (Aínda que hoxe, para esa conformación, os Estados deban ceder parte da súa soberanía).

Razón para que na base do pensamento rousseauniano apareza reiteradamente a cuestión da conciencia cívica e política nacional: «Se todos son iguais pola constitución do Estado, deben ser educados xuntos e da mesma maneira; e se non se pode establecer unha educación pública totalmente gratuita, polo menos haberá que poñela a un prezo que os pobres poidan pagar...». E refírese despois a un sistema de axudas ó estudio. Axudas "ás que os franceses - di- chaman bourses». Os que ocuparían estas prazas na educación nacional serían chamados nenos do Estado (sistema de gratuidade que, por outra

10 Considérations sur le gouvernement de la Pologne, en Oeuvres Complètes, cit. pp. 527-569, [Artigo «Education», pp. 533-535].

11 lbídem, p. 533. 
parte, aborda tamén informalmente en certos pasaxes das Confesións e a propósito dos seus propios fillos, internados en centros de acollida do Estado).

Pero o máis significativo desta pasaxe consiste en que serviría de inspiración e modelo para o Rapport sobre educación, elaborado por Lepelletier de Saint-Fargeau e defendido entusiasticamente por Robespierre na Asemblea Nacional, nos días álxidos da Revolución. O Tributo a Esparta neste Rapport é evidente, pero a filosofía igualitarista e rousseauniana de fondo é o máis importante. Desde aquela, o peso do Estado nos sistemas educativos será cada vez maior (a pesares das amargas críticas de Marx).

Sempre a cabalo entre a revolución e a reforma, entre o desexable e o posible, Rousseau, consciente das limitacións da maquinaria daquel Estado que debía nacer, fala despois da necesidade e conveniencia da posta en marcha de "centros de convivencia" que atendan á formación de nenos e mozos en espazos públicos:

Non se debe permitir que [os rapaces e os mozos] xoguen por separado, senón todos xuntos e en público, de maneira que exista sempre un obxectivo común ó que todos aspiren e que exista a concorrencia e a emulación. Os pais que prefiran a educación doméstica... deben, sen embargo, mandalos a estes exercicios. A súa instrución pode ser doméstica ou particular, pero os seus xogos deben ser sempre públicos e comúns a todos. ${ }^{12}$

Distinción conxuntural entre o público e o privado, mentras se produce a transición do vello Estado ó Estado novo. Isto é, mentras se establecen e se consolidan as novas características nacionais. Rousseau limítase a dibuxar os trazos grosos do sistema educativo polaco, pero non deixa de suliñar as características e a importancia das institucións e dos cargos directivos do novo sistema:

Sexa cal sexa a forma que se lle dea á educación pública —e da que non entro en detallesconvén que exista un órgano supremo de administración e goberno, con centros educativos e cargos elixibles - por méritos-e sempre revocables. ${ }^{13}$

E remata:

Como destes establecementos depende a esperanza da república, a gloria e o destino da nación, a min parécenme dunha importancia tal que estou sorprendido de que ninguén se teña ocupado disto en ningunha parte. ${ }^{14}$

Como colofón xurídico-político da importancia que el lle concede ó funcionamento do sistema educativo, engade:

Sen estes requisitos [c'ést ici l'article important], non agardedes nada das vosas leis; por moi prudentes e previsoras que poidan ser, resultarán inútiles. ${ }^{15}$

12 Ibídem, p. 534.

13 Ibídem, p. 535.

14 Ibídem.

15 Ibídem. 
O breve e condensado artigo sobre «Educación» conclúe: Voilà des preliminaires que j'ai cru indispensables... Unha apertada lección de socioloxía histórica do filósofo de Xenebra.

\section{Post-Scriptum}

¿Sería hoxe unha extrapolación abusiva do pensamento de Rousseau afirmar que sen a consolidación e o dereito á autodeterminación das nacións europeas sen Estado -as pequenas e grandes patrias - e sen a reestruturación sobre novas bases dos Estados afectados, non é posible a solución da cuestión nacional, nin da cuestión social que a ela subxace, nin tampouco unha hipotética construción de Europa?

(Publicado n'A Trave de Ouro, núm. 25, 1996, páxs. 27-36.) 